\title{
Analysis on the Reform of Transmission and Distribution Price and Its Impact on Power Grid Investment
}

\author{
Yuanhui Huang ${ }^{1}$, Dunnan $\mathrm{Liu}^{2}$, Xiaokui $\mathrm{Su}^{3}$ and Luqing Liu ${ }^{4, *}$ \\ ${ }^{1}$ Zhongshan power supply bureau, Zhongshan City, P. R. China \\ ${ }^{2}$ North China Electric Power University, Beijing City, P. R. China \\ ${ }^{3}$ Zhongshan power supply bureau, Zhongshan City, P. R. China \\ ${ }^{4}$ North China Electric Power University, Beijing City, P. R. China \\ ${ }^{*}$ Corresponding author
}

\begin{abstract}
In the reform of the power system for more than a decade, China's power market to participate in the main body has been in the power generation side to form a multi-subject competition situation, but the transmission, distribution, sale of vertical integration of the monopoly situation still exists, the electricity price and sales price is Government to develop. But with the advance of the new round of electricity reform, "the electricity price and sales price generated by the market, transmission and distribution price from the government pricing," the reform direction means that the grid is no longer making a difference, to restore its public utility properties. This paper analyzes the impact of transmission and distribution price reform on the investment strategy of power grid, and studies the economic evaluation of power investment investment decision in the environment of transmission and distribution price reform.
\end{abstract}

Keywords-transmission and distribution price reform; grid investment; optimal decision

\section{INTRODUCTION}

Since the beginning of 2014, Shenzhen City, the establishment of transmission and distribution price reform pilot, and then establish an independent transmission and distribution price system, which is the first step in the power market reform is the most critical step ahead. This move has released a strong signal of the country's market for electricity reform. The future operation of the grid business model will be market-oriented, which is released by the program of the national power system reform development direction. Next, on the basis of the pilot project of the transmission and distribution price reform in Shenzhen, the state will summarize the pilot experience and further improve the opinions and suggestions on the reform of the transmission and distribution policy, and create the conditions for comprehensively promoting the reform of the transmission and distribution price.

With the first batch of transmission and distribution price reform pilot landing, China has initially established a power grid based on the effective assets to ensure the safe operation of power grid to meet the needs of the independent power transmission market price mechanism to achieve the power grid enterprise regulatory model changes. 2016, March 29, the National Development and Reform Commission held on the transmission and distribution price reform conference, the pilot to further expand the 12 provincial power grids and a regional power grid[1-2].

\section{ANALYSIS ON THE INFLUENCE OF TRANSMISSION AND} DisTRIBUTION PRICE REFORM ON POWER GRID INVESTMENT

Before the reform of power transmission and distribution, electricity prices are mainly regulated by the government approved the electricity price and sales price. Now the pilot of the transmission and distribution price reform, the government pricing is mainly limited to important public utilities, public service, network-based monopoly of such links. Power grid is a typical network of natural monopoly, this time to carry out the transmission and distribution price reform is to regulate the power transmission and distribution links, that is, in accordance with the 'custody of the middle, let go of the two' principle, the development of intermediate links Electricity price.

From the transmission and distribution price reform program can be seen that the government approved and government regulation is the core of the new price mechanism, but also the impact of power grid planning is the essence. The permitted income in the accounting of the transmission and distribution price is directly related to the effective assets of the grid's available income, and the effective assets are specifically approved by the government price department. The approval right of the effective assets will cause the planning objectives and constraints of the grid company Change, thus affecting the power grid planning ideas. In the original price mechanism, the goal of power grid planning is mainly to meet the regional power supply and power grid company business development, power grid planning a higher degree of self-decision. The principle of planning is to meet the power supply needs of the grid, pay attention to improve the safety and reliability of power grid operation and take into account the economy, taking into account the international and domestic advanced grid and other factors.

\section{A. Transmission and Distribution Price Mechanism [3]}

Under the new transmission and distribution mechanism, the final decision-making power of the grid plan is in the hands 
of the government. In addition to ensuring that the grid power supply to meet the social and economic needs, the Government should also pay attention to the user can bear the price. All government-approved investments will be included in the electricity price accounting system, the government to reduce the transmission and distribution price, may not pursue too high technical indicators; at the same time will strengthen the planning and project review, there are national or industry standards to adjust the company's Planning the possibility of the project.Reflected in the planning principles and standards, the initial estimate, on basis of meeting the basic power supply needs, the government's economic planning requirements for power grids will be increased, and will no longer pursue operational reliability as the main development goals; in the grid planning Indicators, it will be subject to governmentrelated indicators shall prevail, and the international advanced grid enterprise standards may be some differences.

\section{B. The scale of investment}

In terms of the scale of investment, under the original electricity price mechanism, the investment idea of the grid company is mainly to meet the national macroeconomic situation and the overall requirements of enterprise development, and electricity growth, profit growth, assetliability ratio and other indicators to match. By the comprehensive plan and a comprehensive budget to measure investment capacity, in the case of investment capacity as much as possible to meet the investment needs of power grid planning and construction. In the power system reform, the grid investment is included in the price, subject to government regulation, the Government in order to control the transmission and distribution price, may wish to meet the power supply requirements under the premise of reducing investment.

\section{The Investment Classification Arrangement [4]}

In the investment classification arrangement, under the original price mechanism, the grid companies, in the investment classification arrangements, will give priority to meet the needs of the main business development, to the rapid growth of electricity, high efficiency assets in the region, in order to facilitate investment maximization. At the same time, in terms of investment arrangements in different project categories, the investment effect and construction period should be considered comprehensively, and the investment of all kinds of projects will be solved in an orderly manner to solve the stock problem, meet the load growth, optimize the grid structure and eliminate the operational risk. Under the new transmission and distribution mechanism, the grid company will pay more attention to whether the new investment can form effective assets. The investment classification of the grid company may be based on the priority to meet the development needs of the main business on the basis of the same, more inclined to the formation of effective assets in the field of investment; the same time, taking into account the relevant government supervision and evaluation standards, the total investment Circumstances, it may be prioritized to solve the stock problem items, to meet the power requirements of the first project and bear the social responsibility projects such as easy to form effective assets of the project.
At present, the main measures implemented in the management of planning projects are:

- Three sets of planning. In the five-year plan of the grid, the grid planning is carried out according to the three investment capacity levels of high, medium and low to meet the different grid operating standards and enterprise investment ability.

- Project classification. In the annual rolling planning and five-year plan, the planning projects are classified according to the principle of "priorities" and the classification strategy of the investment strategy, so as to facilitate the investment decision of the project.

Under the existing electricity price mechanism, the planning process of the above-mentioned planning work is relatively high, and the power grid planning is more important to improve the reliability of the power supply, support the development of the company's business and the gradual realization of the enterprise's first goal. Specific project investment efficiency and return on investment and other considerations is not very full, planning management is relatively loose.

Under the new transmission and distribution mechanism, the total investment may be gradually decreasing trend, and the specific investment to be strictly regulated by the government, the specific project investment efficiency and return on investment and other requirements to improve, in the face of many old and new constraints To meet the power grid development of the demand for investment, the development of power grid planning will also put forward higher requirements.

\section{EVAluATION INDEX OF POWER SUPPLy INVESTMENT DECISION - MAKING IN THE ENVIRONMENT OF TRANSMISSION AND DisTRIBUTION PRICE REFORM[5-6]}

\section{A. Investment Rate of Return}

Investment rate of return refers to the ratio of net income to total investment in the normal production year. The general expression is:

$$
\mathrm{R}=\frac{N B}{K}
$$

$\mathrm{K}$ said that the total amount of investment, according to different analytical purposes, $\mathrm{K}$ can be the total amount of investment, or the amount of equity investment of investors; $\mathrm{NB}$ refers to the net profit of the normal production year, according to different analytical purposes, NB can be profit, can be the total amount of profits tax, or the annual net cash inflow; $\mathrm{R}$ said investment rate of return, according to the different meaning of $\mathrm{K}$ and NB, manifested in different specific forms.

The common forms of investment rate of return are: 
Total investment rate of return=

Annual profit+Depreciation and amortization+Interest expense

Total investment

Equity investment rate of return=

Annual profit+Depreciation and amortization Equity investment

Investment tax rate $=\frac{\text { Annual profit }+ \text { Tax }}{\text { Total investment }}$

Return on investment $=\frac{\text { Annual profit }}{\text { Equity investment }}$

Among them, for the equity investment rate of return and investment profit margins, there are income before and after the income tax points.

\section{B. Net Present Value(NPV)}

The net present value indicator is an important indicator of the dynamic evaluation of the investment project, which requires the current annual flow of the project to occur during the life of the project. The present value of the net cash flow discounted to the same point in time (usually at the beginning) is the net present value at a certain depreciation rate. The net present value is expressed as:

$$
\mathrm{NPV}=\sum_{t=0}^{n}(C I-C O)_{t}\left(1+i_{0}\right)^{-t}=\sum_{t=0}^{n}\left(C I-K-C O^{\prime}\right)_{t}\left(1+i_{0}\right)^{-t}
$$

NPV represents the net present value, CIt represents the cash inflow in year $\mathrm{t}$, COt represents the cash outflow in year $\mathrm{t}$, $\mathrm{Kt}$ represents the investment expenditure for year t, and CO't represents the cash outflow except for investment expenditure, $\mathrm{n}$ is used to represent the life of the project, and $\mathrm{i}_{0}$ is the basic discount rate.

For a single scenario, if NPV $\geqslant 0$, the item should be accepted; otherwise it should be rejected. Multi-program must be selected, the net present value of the project is relatively better, that is, the maximum net present value of the standard.

Net present value indicators for multi-program comparison options, regardless of the size of the program investment, can not directly reflect the efficiency of the use of funds. In order to examine the efficiency of the use of funds, people usually use the net present value index (NPVI) as a supplementary indicator of net present value. The net present value index is the ratio of the net present value of the project to the present value of the total investment. The formula is:

$$
N P V I=\frac{N P V}{K_{P}}=\frac{\sum_{t=0}^{n}(C I-C O)_{t}\left(1+i_{0}\right)^{-t}}{\sum_{t=0}^{n} K_{t}\left(1+i_{Q}\right)^{-t}}
$$

$\mathrm{Kp}$ represents the total investment present value of the project.

The net present value indicator has the same criterion as the net present value.

\section{Payback Period}

The payback period is from the date of project construction, with the project annual net income (annual income reduction) will be the total investment recovery period, that is, the following formula TP is the investment recovery period.

$$
\sum_{t=0}^{T_{T}} N B_{t}=\sum_{t=0}^{T_{T}}(B-C)_{t}=\mathrm{K}
$$

$\mathrm{Bt}$ represents the income of year $\mathrm{t}, \mathrm{Ct}$ represents expenditure in year $t, \mathrm{NBt}$ represents net income at year $\mathrm{t}$, and $\mathrm{K}$ represents total investment.

The investment recovery period can also be calculated based on the cash flow statement used in the financial analysis of the investment project. The formula is as follows:

$$
\mathrm{Tp}=\frac{\begin{array}{c}
\text { The cumulative net cash flow of } \\
\text { the absolute value for }(\mathrm{T}-1) \text { years }
\end{array}}{\text { Net cash flow for year } \mathrm{T}}
$$

\section{Internal Rate of Return(IRR)}

The internal rate of return is the discount rate when the total amount of capital inflows is equal to the total amount of capital flows and the net present value is equal to zero. The internal rate of return can be obtained by solving the following equation:

$$
N P V(I R R)=\sum_{t=0}^{n}\left(\begin{array}{ll}
C I & C O
\end{array}\right)_{\tau}(1 \mid I R R)^{-\tau}=0
$$

In the formula, IRR is the internal rate of return.

When the item is judged and optimized by the internal rate of return, it is necessary to set the basic discount rate $\mathrm{i}_{0}$. If IRR $\geqslant \mathrm{i}_{0}$, then the project is economically acceptable; if IRR $<\mathrm{i}_{0}$, the project is economically unacceptable.

\section{E. Life Cycle Cost (LCC)}

Life cycle cost refers to all costs associated with the product during the effective use of the product, including product design costs, manufacturing costs, procurement costs, cost of use, maintenance costs, and disposal costs. The core of the life cycle cost management is that the research and production cost (purchase cost) of the single product is not enough to explain the total cost of the product, and the decision maker should not consider the purchase fee and the maintenance fee separately. Together, as a whole life cycle cost of the product to consider the overall. The Life cycle cost can be calculated by the following model:

$$
\mathrm{LCC}=\mathrm{CI}+\mathrm{CO}+\mathrm{CM}+\mathrm{CF}+\mathrm{CD}
$$

In the formula, CI represents the investment cost, $\mathrm{CO}$ represents the operating cost, $\mathrm{CM}$ represents the maintenance cost, $\mathrm{CF}$ represents the maintenance cost, and CD represents the waste disposal cost. 


\section{Study On InVESTMEnt Decision OF POWER GRID} UNDER REFORM OF TRANSMISSION AND DISTRIBUTION PRICE[7]

In the transmission and distribution price reform, the grid investment is no longer only need to meet the load growth need to invest. The scale of investment is also affected by the transmission and distribution price, the new investment under the approved transmission and distribution price is the source of the actual new investment. Therefore, the transmission and distribution price can be used to estimate the amount of new investment is a range of the upper and lower limits. The scope of the new investment is mainly determined by the depreciation at the beginning of the year and the allowable income at the beginning of the year. In the transmission and distribution price reform, the power grid investment capacity can be calculated by the following formula:

The power grid investment capacity of the current year

$=$ The depreciation at the beginning of the year

+the allowable income at the beginning of the year

This paper chooses the benefit cost ratio to choose the investment scheme of power grid. The cost-benefit ratio is the ratio of the present value of the project to the present value of the present value. The formula is:

$$
(B / C)=\frac{\sum_{t=0}^{n} B_{t}(1+i)^{-t}}{\sum_{t=0}^{n} C_{t}(1+i)^{-t}}
$$

In the formula, $(\mathrm{B} / \mathrm{C})$ is the cost-income ratio, Bt represents the income of the project in the year $\mathrm{t}, \mathrm{Ct}$ represents the cost of the project in the year $t$, $i$ represents the benchmark discount rate, $n$ indicates the life span of the project or the number of years.

When evaluating a single item, the evaluation criteria are: if $(\mathrm{B} / \mathrm{C}) \geqslant 1$, the item is acceptable; if $(\mathrm{B} / \mathrm{C})<1$, the item is unacceptable.

Comparing the mutex scheme with the cost-benefit ratio method can not be compared with the maximum cost of the proceeds, that is, the cost-benefit ratio can not be considered as the best scheme, which is similar to the maximum rate of internal rate of return. The correct approach is to use incremental cost-benefit ratio:

$$
(\Delta B / \Delta C)=\frac{\sum_{t=0}^{n} B_{k t}(1+i)^{-t}-\sum_{t=0}^{n} B_{j t}(1+i)^{-t}}{\sum_{t=0}^{n} C_{k t}(1+i)^{-t}-\sum_{t=0}^{n} C_{j t}(1+i)^{-t}}=\frac{\Delta B}{\Delta C}(14)
$$

In the formula, $(\Delta \mathrm{B} / \Delta \mathrm{C})$ is the incremental benefit cost ratio, $B_{k t}, C_{k t}$ is the benefit and cost of the $\mathrm{k}$ scheme in the year $\mathrm{t}$, and $\mathrm{B}_{\mathrm{jt}}, \mathrm{C}_{\mathrm{jt}}$ is the benefit and cost of the $\mathrm{j}$ scheme in the year $\mathrm{t}$.

The evaluation criteria are as follows: if $(\Delta \mathrm{B} / \Delta \mathrm{C})>1$, then the project of big present value is good; if $(\Delta \mathrm{B} / \Delta \mathrm{C})<1$, the benefit is small.

\section{CONCLUSION}

This paper first analyzes the impact of transmission and distribution price reform on the investment of power grid enterprises, and expounds the development direction of power grid enterprises under the new environment. And then the investment decision of the power grid enterprises were studied, and the investment decision method based on the income cost ratio method was put forward. However, there are still many shortcomings in the data mining, the actual argument still needs further study, the future consider in-depth data mining, optimize the decision-making program to build the optimal investment decision of power grid under the reform of transmission and distribution price.

\section{REFERENCES}

[1] Zheng Xinye. Strengthen the supervision of capacity-building to promote the transmission and distribution price reform [J]. Price theory and practice, 2016 (2).

[2] Zhang particle. China's power transmission and distribution reform in the mechanism of construction and method of exploration [J]. Price theory and practice, 2016 (2).

[3] Ye Ze. Current China's power transmission and distribution reform effectiveness, problems and countermeasures [J]. Price theory and practice, 2016 (02): 35-42.

[4] Dong Hong, Liu Wenge, Zhu Zhifang. Impact of power transmission and distribution reform on Guangzhou power grid planning and its countermeasures [J] .Guangdong Electric Power, 2016 (05): 42-45 + 66.

[5] Yang Jing, Xiang Xiaodong, Wu Gaoming, et al. Application of reliability allocation theory in system security target implementation [J]. Chinese Journal of Safety Science, 2007, (12): 142-146, 195.

[6] Li Ying, transmission and distribution price theory and practice, Beijing: China Electric Power Press, 2011

[7] Bai Mei, He Aimin. Developed countries, transmission and distribution price control theory practice and experience reference $[\mathrm{J}]$. Price theory and practice, $2016(3)$ 